\title{
A New Approach to Improve Induction Motor Performance in Light-Load Conditions
}

\author{
Sadegh Hesari ${ }^{\dagger}$ and Aghil Hoseini*
}

\begin{abstract}
Induction motors often reach their maximum efficiency at the nominal load. In most applications, the machine load is not equal to the nominal load, thus reduces the motor efficiency and turns a greater percent of power into loss. In this paper, the induction motor control problem has been investigated to reduce the system losses. The Field Oriented Control method (FOC) has been employed in this paper. In this research, the mathematical equations related to system losses are calculated in relation to torque and speed, and then the q- and d-axis are summarized according to the current components. After that, the proposed method is applied along with d- and q-axis. In the recent three decades, many techniques have been suggested to improve the induction motor performance using smart and non-smart methods. In this paper, a new PSO-Fuzzy method have used in real time. The fuzzy logic method serves as speed controller in q-axis and PSO algorithm controls the optimum flux in d-axis. It will be proved that the use of this combined method will lead to a significant improvement in motor efficiency.
\end{abstract}

Keywords: Induction motor, Light loads, Loss minimization, Flux control, Efficiency improvement

\section{Introduction}

The increased energy consumption while having limited resources and high energy cost, is the main reason for us to reduce the losses of electric systems. On the other hand, the induction motors consume more than $50 \%$ of total electric energy [1-3]. So, given the enormous amount of consumed energy, it is necessary to reduce loss in induction motors, especially in variable speed applications. Since late 1970's, minimizing the losses in electric motors have been discussed as a serious subject. Reviewing the conducted works in this field indicates that the more progress is seen in power electronic and microprocessor devises as the main constituents of loss reduction system, the more progressed and cheaper controlling structure have been achieved for theses system, which provide a better performance; thus the results are more acceptable and applicable [4-6]. It is predicted that, in near future, these systems will become an inseparable part of electric drives. All of the controlling methods related to loss minimization and motor efficiency optimization can be regarded as balancing iron and copper losses in the motor [1,2]. A well-designed induction motor possesses an acceptable efficiency in nominal load and nominal speed; however, in light loads, the induction motor efficiency will drop as a result of lack of balance in copper and iron losses. Novel methods for loss minimization by regulating the controlling variables related to motor try to

$\uparrow \quad$ Corresponding Author: Young Researcher and Elite Club, Bojnourd Branch, Islamic Azad University, Bojnourd, Iran.

(hesari.sadegh@yahoo.com)

* Dept. of Electrical Engineering, Bojnourd Branch, Islamic Azad University, Bojnourd, Iran. (aghil.hosseyni@yahoo.com)

Received: December 6, 2016; Accepted: February 17, 2017 maintain this balance. The emergence of power electronic devices as well as voltage source inverters (VSI), flux control is obtained easily [7-10].

In recent decades, much efforts has been allocated by researches to achieve an appropriate method for optimizing different electric machines, which has resulted in methods such as Genetic Algorithm (GA), Particle Swarm Optimization (PSO), Artificial Neural Networks (ANN), and Fuzzy Logic.

In [6] the Genetic Algorithm has been used to Minimize Losses. The main approach of this paper is to optimize the flux level and/or d-axis current.

In [21], PID Tuning GA controller is used to improve the performance of induction motor drive. In fact, the PI controller parameters, like $\mathrm{kp}$ and $\mathrm{ki}$, are directly regulated by GA. The way this approach works can be seen in the motor drive speed control system. q-axis is considered to improve the drive performance. The objective function of this problem is the motor efficiency. A coefficient of $\mathrm{kp}$ and $\mathrm{ki}$ in each cycle is specified that has the maximum objective function.

In [17] a new technique is presented that can increase efficiency and decrease losses in an induction motor according to PSO algorithm. In this reference, the maximizing efficiency strategy is applied to control the induction motor speed. The suggested technique of this research is based on flux level regulation with a certain load torque and speed. In the control process, PSO algorithm will receive the speed-related load torque and the calculated objective function (efficiency equation), PSO, obtains the slide frequency in the maximum efficiency.

The fuzzy system structure is appropriate for substituting 
P, PD, PI, and PID controller. In references [18-19] a Fuzzy Logic is used to speed control, i.e. q-axis or $T_{e}$ torque control, in order to maximize the motor efficiency.

References [7,13] have utilized the Fuzzy-Genetic method in order to improve a induction Motor Efficiency. $\mathrm{d}$-axis is controlled using the Genetic Algorithm and q-axis is controlled by the Fuzzy Logic.

In this paper, the total loss to torque and speed ratio is calculated, and then, using PSO algorithm, isd current is regulated momentarily. The Fuzzy Logic is also used as a speed controller. Next, in the Section 2, the mathematical model of the induction motor is summarized along with its relations. Then, in Section 3, the loss minimization algorithm is stated according to LMC algorithm. The proposed model of the paper, together with the analysis and results, are presented in Sections 4 and 5, respectively.

\section{The Induction Motor Model}

Induction motors are often introduced by power, nominal speed, voltage and frequency. The motor used in this research is related to a $4-\mathrm{Kw}$ induction motor. Table 1 shows the characteristics of this motor. This motor possesses these characteristics: power: $4 \mathrm{Kw}$, frequency: $50 \mathrm{~Hz}$, Voltage: 380 or $660 \mathrm{~V}$, and Efficiency: $88 \%$ in nominal mode.

The control model used in this research follows the rotor

Table 1. The motor characteristics

\begin{tabular}{c|c}
\hline \multicolumn{2}{c}{ motor $4 \mathrm{kw}, 1440 \mathrm{rpm}, 380 / 660 \mathrm{v}$} \\
\hline rotor resistance $=1.083(\mathrm{ohm})$ & Stator resistance $=1.115(\mathrm{ohm})$ \\
\hline rotor inductance $=0.0059(\mathrm{H})$ & stator inductance $=0.0059(\mathrm{H})$ \\
\hline Inertia $=0.02\left(\mathrm{~kg} . \mathrm{m}^{2}\right)$ & Mutual inductance $=0.2037(\mathrm{H})$ \\
\hline friction factor $=0.005752(\mathrm{~N} . \mathrm{m} . \mathrm{s})$ & pole pairs $=2$ \\
\hline
\end{tabular}

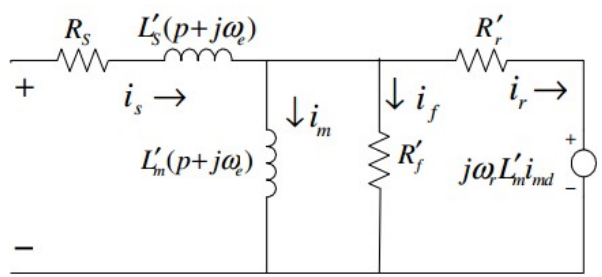

Fig. 1. The equivalent circuit of induction motor including iron loss resistance

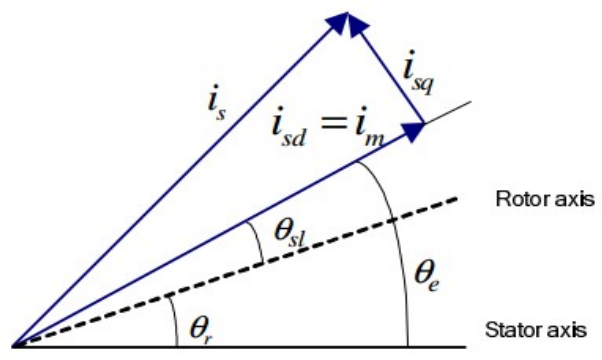

Fig. 2. The Phasor diagram of the equivalent circuit and the rotor field angels flux. Modeling and formulation of this methods will be presented later. In this simulation, an equivalent circuit is used, which points to the rotor magnetic current. An iron loss resistance $R_{f}^{\prime}$ is connected in parallel to the magnetizing inductance in rotor flux reference frame, which can be seen in Fig. 1 [1-2].

We define the derivation operator as $\mathrm{p}=\frac{d}{d t}$. The motor model in vector mode in rotor frame is presented in Eq. (1) and (2), where $W e=\frac{d \theta e}{d t}$ is the rotor flux electric angular speed and $W r=\frac{d \theta r}{d t}$ denotes the rotor electric speed [1]:

$$
\begin{aligned}
& u_{s}=R_{s} i_{s}+p L_{s}^{\prime} i_{s}+j \omega_{e} L_{s}^{\prime} i_{s}+p L_{m}^{\prime} i_{m}+j \omega_{e} L_{m}^{\prime} i_{m} \\
& i_{s}=i_{m}+i_{f}+i_{r}=i_{m}+\left(p+j \omega_{e}\right) \frac{L_{m}^{\prime}}{R_{f}^{\prime}} i_{m}+ \\
& \left(p+j\left(\omega_{e}-\omega_{r}\right)\right) \frac{L_{m}^{\prime}{ }_{R_{r}^{\prime}}}{i_{m} .}
\end{aligned}
$$

Using $u_{s}=u_{s d}+j u_{s q}, \quad i_{s}=i_{s d}+j i_{s q}, \quad i_{m}=i_{m d}+$ $j i_{m q}, i_{m q}=0$ and $i_{m d}=i_{m r}=$ Constant for the structure of rotor flux field control from Eq. (1) and (2), we have:

$$
\begin{aligned}
& u_{s d}=R_{s} i_{s d}+p L_{s}^{\prime} i_{s d}-\omega_{e} L_{s}^{\prime} i_{s q}+p L_{m}^{\prime} i_{m r} \\
& u_{s q}=R_{s} i_{s q}+p L_{s}^{\prime} i_{s q}+\omega_{e} L_{s}^{\prime} i_{s d}+\omega_{e} L_{m}^{\prime} i_{m r} \\
& i_{s d}=i_{m r}+p\left(\frac{L_{m}^{\prime}}{R_{f}^{\prime}}+\frac{L_{m}^{\prime}{ }_{m}}{R_{r}^{\prime}}\right) i_{m r} \\
& i_{s q}=\omega_{e} \frac{L_{m}^{\prime}}{R^{\prime}{ }_{f}} i_{m r}+\left(\omega_{e}-\omega_{r}\right) \frac{L_{m}^{\prime}{ }_{R_{r}}}{R_{m r}} i_{m r} .
\end{aligned}
$$

Substituting

$$
R_{t}=R_{r}^{\prime} \| R_{f}^{\prime}
$$

The magnetic current is:

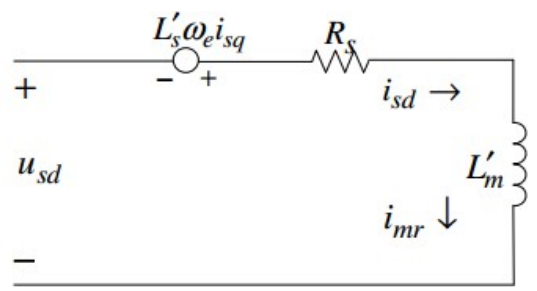

(a) Equivalent axis of d-axis

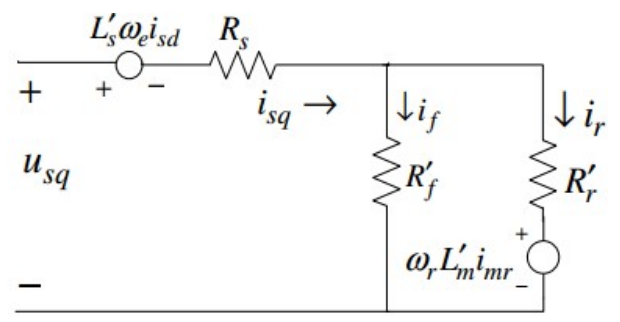

(b) Equivalent axis of q-axis

Fig. 3. The equivalent circuit of permanent-mode motor 


$$
i_{m r}=\frac{1}{1+p\left(\frac{L^{\prime} m}{R_{f}^{\prime}}+\frac{L^{\prime} m}{R^{\prime} r}\right)} i_{s d}=\frac{1}{1+\frac{L^{\prime} m}{R^{\prime} t}} i_{s d}
$$

From Eq. (3) to (6), the slip speed is:

$$
\omega_{\text {slip }}=\frac{R_{r}^{\prime} r}{L_{m}^{\prime}} \frac{i_{s q}}{i_{m r}}-\omega_{e} \frac{R_{r}^{\prime}}{R_{f}^{\prime}}=\frac{R^{\prime}{ }_{t}}{R_{f}^{\prime}} \frac{i_{s q}}{i_{m r}}-\omega_{e} \frac{R_{t}}{R_{f}}
$$

In steady state mode, there has been no leakage inductance in rotor side and the sum of rotor current $i_{r}$ and iron current $\mathrm{i}_{\mathrm{f}}$ is equal to the magnetic current $\mathrm{i}_{\mathrm{mr}}$. In this case, $\mathrm{i}_{\mathrm{mr}}=\mathrm{i}_{\text {sd }}$, which is as mode of $\psi_{r}$ and we have $i_{s q}=i_{f}+i_{r}$, which is related to torque control. According to Eq. (3) to (6), the equivalent circuit for steady state mode induction motor is shown in Fig. 3. Fig. 3(a) is obtained from Eq. (3) and (5), and Fig. 3B is taken from Eq. (4) and (6).

\section{Loss Minimization Algorithm According to Loss Model Control (LMC) Method}

In order to develop the loss model, a common and simple method has been employed in previous works $[1,2$, 11-13]. Stator copper losses, rotor copper losses and iron losses are considered as total losses, and are stated in Eq. (9):

$$
\begin{aligned}
P_{\text {total }} & =P_{\text {cus }}+P_{\text {iron }}+P_{\text {cur }} \\
& =R_{s}\left(i_{s d}^{2}+i_{s q}^{2}\right)+R_{f}^{\prime}\left(i_{s q}+i_{r}\right)+R_{r}^{\prime} i_{r}^{2}
\end{aligned}
$$

where $\mathrm{p}_{\text {cus }}$ is the stator copper losses, $\mathrm{p}_{\text {iron }}$ the iron losses, and $\mathrm{p}_{\text {cur }}$ the rotor copper losses. When the only real variables are stator current and voltage, we need to obtain the total losses in terms of $i_{\text {sd }}$ and $i_{\text {sq }}$ current. From Fig. 3, the rotor current is:

$$
i_{r}=i_{s q}-i_{f}=i_{s q}-\frac{R_{r}^{\prime} r}{R_{f}^{\prime}} i_{r}-\omega_{r} \frac{L_{m}^{\prime}}{R_{f}^{\prime}} i_{s d}
$$

So we have:

$$
i_{r}=\frac{R_{f}^{\prime}}{R^{\prime} f^{+R^{\prime} r}} i_{s q}-\omega_{r} \frac{L_{m}^{\prime}}{R_{f}^{\prime}+R_{r}^{\prime} r} i_{s d}
$$

By substituting the ir relation in Eq.(9), we have:

$$
P_{\text {total }}=R_{d} i_{s d}^{2}+R_{q} i_{s q}^{2}
$$

where

$$
R_{d}=R_{s}+\frac{L_{m}^{\prime 2}}{R_{f}^{\prime}+R_{r}^{\prime}} \omega_{r}^{2}, R_{q}=R_{s}+\frac{R_{f}^{\prime} R_{r}^{\prime}}{R_{f}^{\prime}+R_{r}^{\prime}}
$$

It can be seen that $\mathrm{R}_{\mathrm{d}}$ is dependant upon $w_{r}$ speed. The torque relation is:

$$
\begin{aligned}
T_{e} & =\frac{3}{2} Z_{p} L_{m}^{\prime} i_{m r} i_{r} \\
& =\frac{3}{2} Z_{p} L_{m}^{\prime}\left(\frac{R_{f}^{\prime}}{R^{\prime} f^{+R^{\prime} r}}\right) i_{s q} i_{m r}-\frac{3}{2} Z_{p} \frac{\left(L_{m}^{\prime} i_{m r}\right)^{2}}{R_{f^{\prime}+R^{\prime} r}} \omega_{r}
\end{aligned}
$$

So that we can have:

$$
\begin{aligned}
T_{e} & =\frac{3}{2} Z_{p} \frac{\left(L_{m}^{\prime} i_{m r}\right)^{2}}{R_{f}^{\prime}+R_{r} r} \omega_{\text {slip }} \\
& =\frac{3}{2} Z_{p} L_{m}^{\prime} i_{m r} i_{s q}-\frac{3}{2} Z_{p} \frac{\left(L_{m}^{\prime} i_{m r}\right)^{2}}{R_{f}^{\prime}} \omega_{e}
\end{aligned}
$$

If the second sentence in Eq.(10) is used in Eq.(14), then the torque relation Eq.(14) would be similar to Eq.(13). The second sentence in Eq.(14) is related to torque losses, which is dependent on iron losses resistance.

When $R_{f}^{\prime} \gg R_{r}^{\prime}$ and $\left(R_{f}^{\prime}+R_{r}^{\prime}\right) \gg\left(L_{m} i_{m r}\right)^{2}$, the torque relation Eq.(14) is approximated as:

$$
T_{e}=\sim \frac{3}{2} Z_{p} L_{m}^{\prime} i_{m r} i_{s q}=K_{t} i_{m r} i_{s q}
$$

where:

$$
K_{t}=\frac{3}{2 Z_{p} L_{m}^{\prime}}
$$

In steady state mode we have:

$$
i_{s q}\left(i_{s d}\right)=\frac{T_{e}}{K_{t} i_{s d}}
$$

The derivative of Eq.(12) in relation to $i_{\text {sd }}$ is obtained as:

$$
\begin{gathered}
\frac{d P_{\text {total }}}{d i_{s d}}=2 R_{d} i_{s d}+2 R_{q} i_{s q}\left(i_{s d}\right) \frac{d i_{s q}\left(i_{s d}\right)}{d i_{s d}}=> \\
\frac{d P_{\text {total }}}{d i_{s d}}=2 R_{d} i_{s d}-2 R_{q} \frac{i^{2} s q}{i_{s d}}=0
\end{gathered}
$$

This states that motor loses are minimized if q- and daxis loses are equal. Thus, magnetic current for the minimum losses is defined as:

$$
i_{\text {imr-opt }}=\sqrt{\frac{R_{q}}{R_{d}\left(\omega_{r}\right)}} i_{s q}=K i_{s q}
$$

Where $k$ is the loss coefficient and is considered as:

$$
K=\sqrt{\left(R_{q}\right) /\left(R_{d}\left(\omega_{r}\right)\right)}=\left(i_{\text {imr-opt }}\right) /\left(i_{s q}\right)
$$

\section{Loss Minimization Algorithm According to PSO Algorithm and Fuzzy Logic}

In this paper we will use PSO algorithm and Fuzzy logic simultaneously. In the following subsections, first both of them are briefly defined and the conditions for using them for loss Minimization is explained. In fact, we are 
going to control the flux along d-axis in such a way that the losses along q- and d-axis are balanced. First, PSO algorithm is explained in section 4.1. Then, sections 4.2 and 4.3 explain Fuzzy logic and the general model of the system, respectively.

\subsection{Particle Swarm Optimization Algorithm (PSO)}

PSO is an optimization algorithm based on collective intelligence of birds or particles and is similar to a flock of flying birds. In this method, each particle tries to match its behavior to the behavior of the group and its own previous behaviors in every repetition. Each particle has $d$ dimensions, which is in fact equal to the variables existing in cost function [14-17].

$$
x_{i}=\left(x_{i 1}, x_{i 2}, \ldots, x_{i d}\right)
$$

In this algorithm, the best position taken by a particle until moment $i$ is denoted by pbest. The best position of a particle in the entire population is also denoted by gbest. The rate of variance or the particle speed is considered as:

$$
v_{i}=\left(v_{i 1}, v_{i 2}, \ldots, v_{i d}\right)
$$

In the first replication, a primary generation is produced randomly. Speed and position of each particle in $\mathrm{k}+1$ replication is calculated by:

$$
\begin{gathered}
v_{i d}(k+1)=w v_{i d}(k)+c_{1} r_{1}\left(p_{i d}(k)-x_{i d}(k)\right) \\
+c_{2} r_{2}\left(p_{g d}(k)-x_{i d}(k)\right) \\
x_{i d}(k+1)=x_{i d}(k)+v_{i d}(k+1)
\end{gathered}
$$

In the above relation $i=1,2,3, \ldots, \mathrm{n}$; where $\mathrm{n}$ is the number of particles. The d-dimensional vector $v_{i d}(k)$ denotes the speed of the $i$ 'th particle in the $k$ 'th replication. The d-dimensional vector $x_{i d}(k)$ shows the position of $i^{\prime}$ th particle in the $k$ 'th replication. The d-dimensional vector $p_{i d}$ denotes the best position of pbest for the $i$ 'th particle in the $k$ 'th replication. The d-dimensional vector $p_{g d}$ shows the best position among all particles or gbest in the $k^{\prime}$ th replication. $c_{1}$ and $c_{2}$ are learning factors. $\omega$ shows inertia factor and is a positive constant. $r_{1}$ and $r_{2}$ are random numbers in $(0,1)$ window. Eg. (21) and (22) show how each particle sets its speed and position [16-17].

The adjustable parameters in PSO algorithm are the number of particles $m$, inertia factor $\omega$, learning factors $c_{1}$ and $c_{2}$, and the maximum number of replications $N$. Table 2 lists the simulation parameters. In this paper:

- $\left\{i_{s d}\right\}$ the i'th particle (d-axis current as particle);

- $\left\{\right.$ pbest $\left._{i s d}\right\}$ the best position found for the i'th particle;

The best position for the i'th particle and the best position for a batch of particles is obtained through the Eq. (23). One problem that existed in LMC was to use
Table 2. The selected parameters of PSO algorithm

\begin{tabular}{c|c}
\hline Parameters & Value \\
\hline Inertia parameter $(\omega)$ & rand \\
\hline Learning factor $\left(\mathrm{c}_{1}\right)$ & 1.5 \\
\hline Learning factor $\left(\mathrm{c}_{2}\right)$ & 1.5 \\
\hline The number of dimensions $(\mathrm{dim})$ & 200 \\
\hline The number of birds $(\mathrm{n})$ & 200 \\
\hline
\end{tabular}

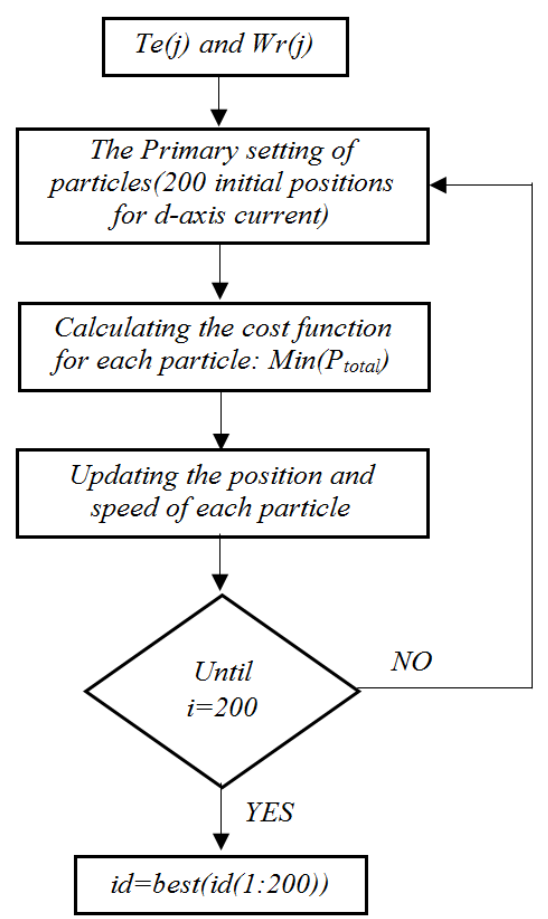

Fig. 4. PSO algorithm flowchart

differentiation, while the PSO algorithm does not need differentiation and/or any type of auxiliary information, and only the objective function and the fitness determinant style for raw information should be specified for search.

Since the problem of LMC method was differentiation, so in this paper this problem is solved by finding the minimum, which is an easier solution. Eq. (17) is rewritten as (23):

$$
\operatorname{Max} \text { efficiency }=\operatorname{Min}\left(P_{\text {total }}\right)
$$

PSO algorithm flowchart is presented in Fig. 4.

\subsection{Fuzzy logic}

Fuzzy logic states the relationships between accuracy and truth or meaning by mathematical functions. Fuzzy systems are based upon the idea of Fuzzy sets. A Fuzzy set, like defined sets, is constituted of a number of elements, where there is no determined boundary between membership and non-membership of the elements. Fuzzy sets allow each member to have a special membership degree in relation to a special set. Fig. 5 presents a fuzzy 
controller [18-19].

In this research, two variables, rotor speed variation $\Delta w$ and its derivative $\Delta \dot{w}$, are used to design the Fuzzy controller. So, a membership function is defined for each of them. The linguistic values considered for them are:

$$
\begin{aligned}
& \mathrm{w}=\{\mathrm{NB}, \mathrm{NS}, \mathrm{ZE}, \mathrm{PS}, \mathrm{PB}\} \mu_{\Delta} \\
& \dot{w}=\{\mathrm{NB}, \mathrm{NS}, \mathrm{ZE}, \mathrm{PS}, \mathrm{PB}\} \mu_{\Delta} \\
& \mathrm{Te}^{*}=\{\mathrm{NB}, \mathrm{NS}, \mathrm{ZE}, \mathrm{PS}, \mathrm{PB}\} \mu
\end{aligned}
$$

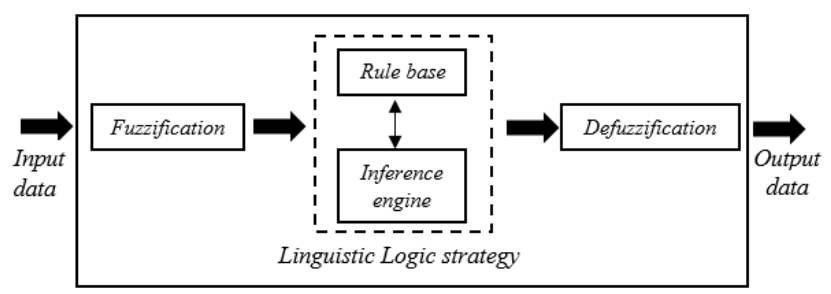

Fig. 5. A fuzzy controller

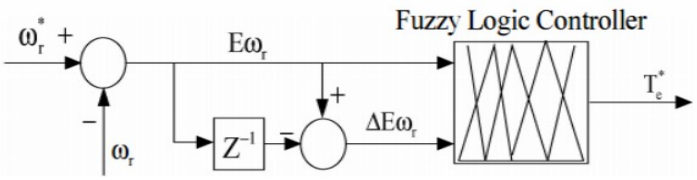

Fig. 6. Controlling system diagram

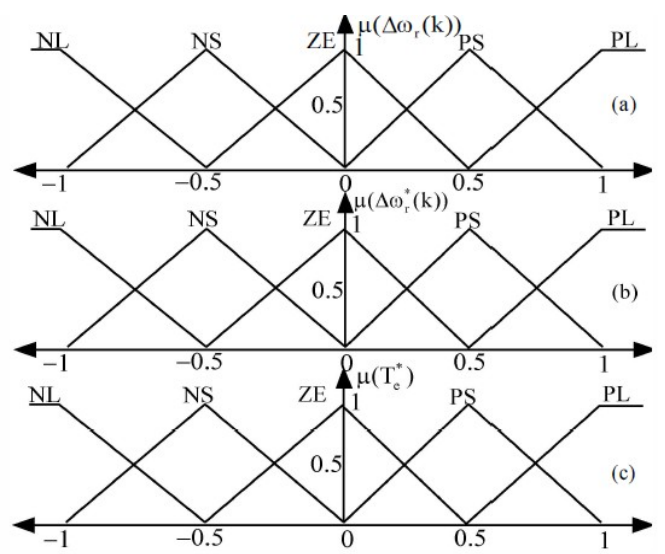

Fig. 7. The input and output membership functions
$\mathrm{N}=$ Negative; $\mathrm{ZE}=$ =ero; $\mathrm{P}=$ Positive; $\mathrm{S}=$ Smal $\mathrm{B}=\mathrm{Big}$

In Figs. 6 and 7, show the functions of input and output membership for the Fuzzy controller. An important point in designing this system is the way a membership function is build. To do this, one can used the operator experience, however it should be bear in mind that the sets should have enough overlapping, otherwise the controller can come across some modes that do not present a good output.

The input and output membership functions are presented in Fig. 7.

Having determined the input and output membership functions of the Fuzzy controller, the knowledge base rules must be set. Fuzzy controller has a total of 25 laws. Fuzzy laws are considered as:

Rj: if ( $E \omega$ is NS and $\Delta E \omega$ is $Z E$ ) then $u$ is $N S$

$\mathrm{J}=1,2, \ldots, 25$

The total set of Fuzzy laws is presented here.

Table 3. Fuzzy laws

\begin{tabular}{c|c|c|c|c|c}
\hline$E \omega$ & NL & NS & ZE & PS & PL \\
\hline NL & NL & NL & NL & NS & ZE \\
\hline NS & NL & NL & NS & ZE & PS \\
\hline ZE & NL & NS & ZE & PS & PL \\
\hline PS & NS & ZE & PS & PL & PL \\
\hline PL & ZE & PS & PL & PL & PL \\
\hline
\end{tabular}

To defuzzify the Fuzzy output, the center of gravity law is used as:

$$
y=\frac{\sum_{j=1}^{25} a_{j} z_{j}}{\sum_{j=1}^{25} z_{j}}
$$

\subsection{The general system model and analysis}

The structure of PSO algorithm and Fuzzy logic to be used in this paper was explained in previous subsections.

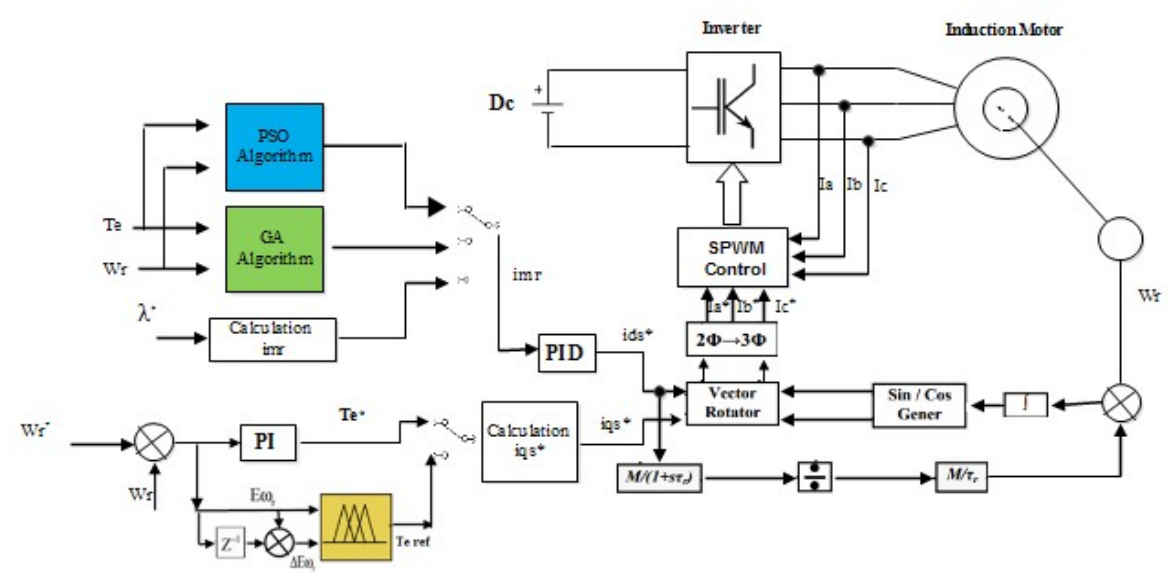

Fig. 8. the block diagram of the system 


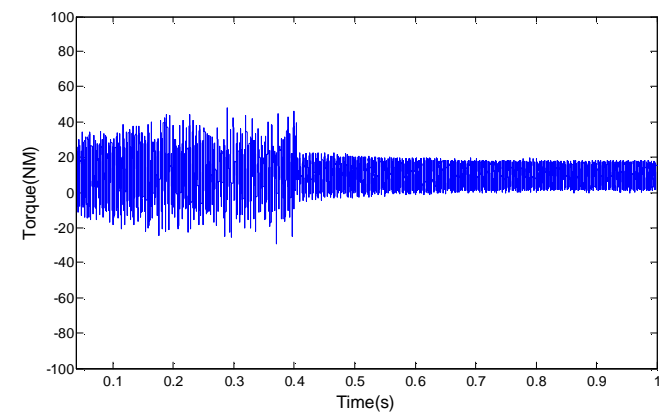

(a) Electromagnetic torque

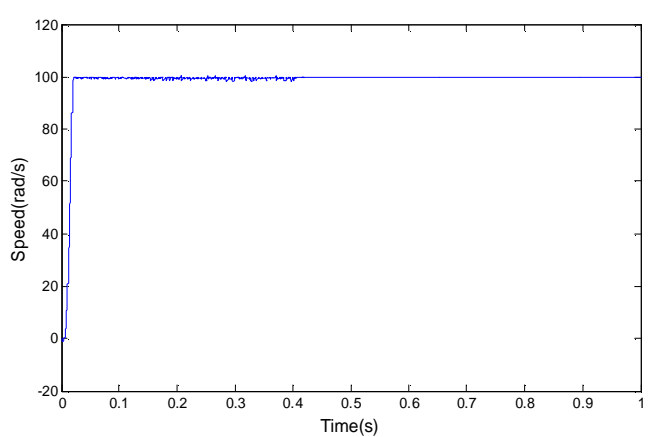

(b) Speed

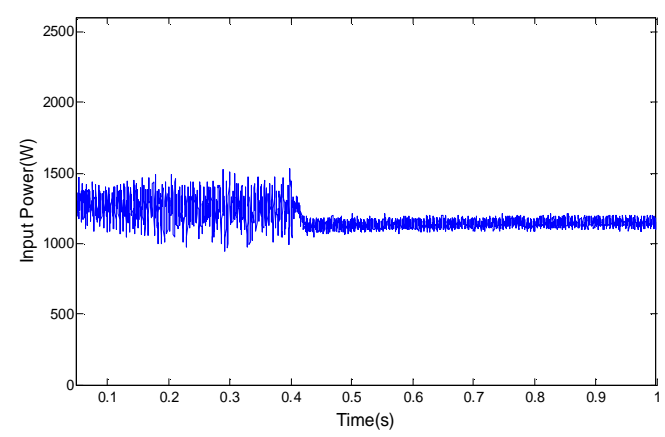

(c) Input power

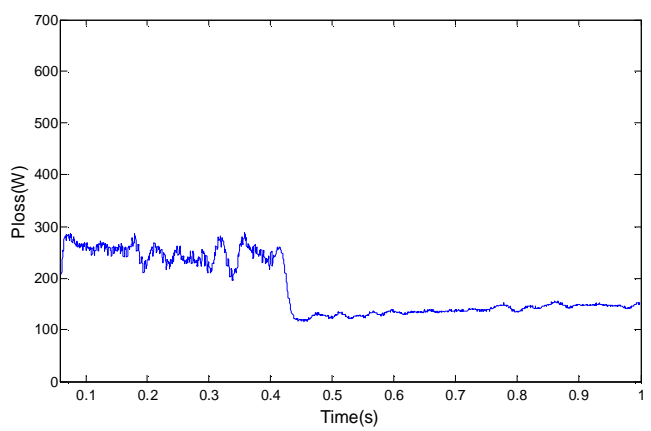

(d) Power loss

Fig. 9. The results of simulation in $10-\mathrm{Nm}$ load in FOC and Fuzzy-PSO modes

The general systemic modeling used in this research is provided in Fig. 8. An induction motor with a feeding inverter is launched by a SPWM switching [20-21]. The amount of reference currents Iabc* is obtained from q- and d-axis by Park inversion. In q-axis, two controllers, $p i$ and Fuzzy logic, are suggested for speed control. The input for

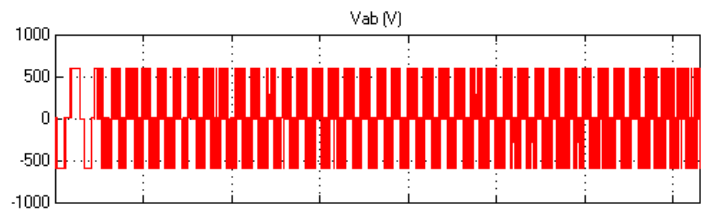

Fig. 10. Points A and B voltage in inverter output (in $25 \%$ of nominal load)

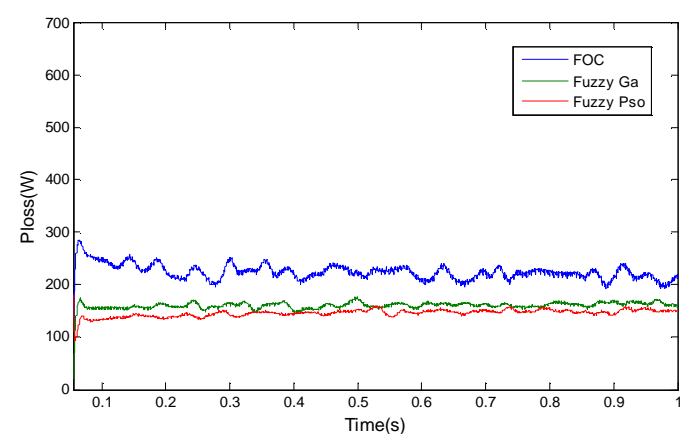

Fig. 11. Losses in three modes (in $25 \%$ of nominal load) in Fuzzy - PSO mode

$p i$ controller is speed error, while the fuzzy inputs include speed error as well as the derivative of speed error. FOC, Genetic and PSO algorithms are also analyzed in d-axis. The input for smart algorithms includes torque and motor speed, which is obtained from output feedback in real time. In this paper a $4-\mathrm{Kw}$ induction motor is used. For the first simulation, the switch is varied between FOC and PSO modes. In about 0.4 second, the switch is on FOC mode, and between 0.4 and 1 second, it is set on Fuzzy and PSO modes. The results of this mode are presented in Fig. 9. The load torque in this status is considered to be $10 \mathrm{Nm}$.

As it can be seen in the results of Fig. 9, when the switch changes from FOC-PI state to PSO-FUZZY state in $\mathrm{t}=0.4$, far better results are obtained. In this state the torque ripple (Fig. 9a), speed ripple (Fig. 9b) and input power ripple (Fig. 9c) are decreased significantly and the motor losses (Fig. 9d) are decreased from 280 to 120 . The reference torque amount in this state is set as $10 \mathrm{NM}$. Now the switch is set in Fuzzy-PSO mode, and some of the results for $25 \%$ of the nominal load are presented in Figs. 10 and 11.

Fig. 10 shows the inverter output for line to line voltage. The load torque is considered as $25 \%$ of nominal load and about 7 NM.

It is obviously observed from Fig. 11 that in $25 \%$ of nominal load the losses in Fuzzy-PSO mode are in a better condition. The simulation is conducted for load torques between 1 and $25 \mathrm{Nm}$. In each mode, the values of Efficiency and Input power are calculated, the results of which are presented in Fig. 12. The horizontal axis is the load torque axis, and the vertical axis is the mean amount of Efficiency and input power in each load.

As it can be seen in above figures, the results are compared in three conditions. FOC mode, Fuzzy-GA mode 


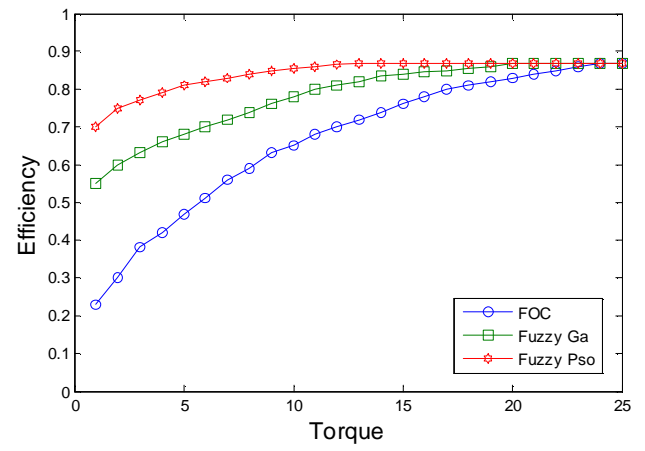

(a) Efficiency

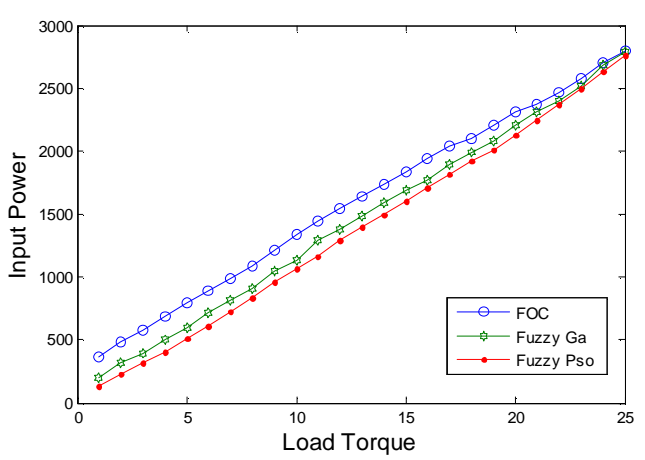

(b) Input power

Fig. 12. The motor Efficiency and input power in relation to torque variation between 1 and $25 \mathrm{Nm}$

and Fuzzy-PSO mode, of which the Fuzzy-PSO mode presented a better Efficiency and input power.

\section{Conclusions}

The increased energy consumption while having limited resources and high energy cost, is the main reason for us to reduce the losses of electric systems. On the other hand, the induction motors consume more than $50 \%$ of total electric energy. So, given the enormous amount of consumed energy, it is necessary to reduce loss in induction motors, especially in variable speed applications.

In this paper the first Section presented an introduction to induction motors. Section 2 described the induction motor used in this research. The loss minimization algorithm, according to LMC algorithm was presented in Section 3. In Section 4, the proposed model of this research, PSO-Fuzzy algorithm, was provided in order to reduce the system losses. Finally, Section 5 concludes the paper.

It was demonstrated in this paper that the proposed algorithm enjoys a high accuracy in reducing losses in induction motors. The reason for this improvement is the simpler control of flux. In this research, it was shown that losses, and consequently efficiency, are dependent directly on rotor electromagnetic current imr. This current is also dependent on flux. So, by controlling the rotor flux, efficiency can be improved in light load conditions. In this research, motor loading was considered to be between 1 and $25 \mathrm{Nm}$. This amount is selected according to the motor characteristics in nominal conditions. The loading conditions of this motor between 1 and $6 \mathrm{Nm}$ can be considered safely as the light load conditions. In these conditions, the efficiency of the motor was improved between 35 and $40 \%$. In $25 \%$ of nominal load, efficiency experienced a $30 \%$ improvement.

\section{References}

[1] M. Nasir Uddin, Sang Woo Nam, "New Online LossMinimization-Based Control of an Induction Motor Drive," IEEE Transactions on Power Electronics, vol. 23, no. 2, MARCH 2008.

[2] Sadegh Hesari, Mohsen Noruzi, Ali Asghar Shojaei, "Investigating the Intelligent Methods of Loss Minimization in Induction Motors," Hindawi publication, 2016.

[3] Rodrigo H. Cunha Paláciosa, Ivan N. da Silvaa, Alessandro Goedtel, "A novel multi-agent approach to identify faults in line connected three-phase induction motors," Applied Soft Computing Volume 45, August 2016, Pages 1-10.

[4] M. Ranjania, P. Murugesanb, "Optimal fuzzy controller parameters using PSO for speed control of Quasi-Z Source DC/DC converter fed drive," Applied Soft Computing vol. 27, February 2015, Pages 332356.

[5] Rup Narayan Raya, Debashis Chatterjeeb, Swapan Kumar Goswami, "A PSO based optimal switching technique for voltage harmonic reduction of multilevel inverter," Expert Systems with Applications vol. 37, no. 12, December 2010, Pages 7796-7801.

[6] Sadegh Hesari, Mohammad Bagher Naghibi Sistani, "Optimizing the Deceased Induction Motor Losses using Genetic Algorithm," Majlesi Journal of Mechatronic Systems, vol. 4, no. 3, September 2015.

[7] Sadegh Hesari, Mohammad Bagher Naghibi Sistani, "Efficiency Improvement of Induction Motor using Fuzzy-Genetic Algorithm," International Journal of Smart Electrical Engineering, vol. 4, no. 2, Spring 2015.

[8] Navneet Kumar, Thanga Raj Chelliah, S. P. Srivastava, "Adaptive control schemes for improving dynamic performance of efficiency-optimized induction motor drives," ISA Transactions, vol. 57, July 2015, Pages 301-310.

[9] Eleftheria S. Sergaki, "Motor Flux Minimization Controller based on Fuzzy Logic Control for DTC AC Drives," International Conference on Electrical Machines-ICEM 2010, Rome.

[10] Shahriyar Kaboli, Mohammad Reza Zolghadri, "A Fast Flux Search Controller for DTC-Based Induction 
Motor Drives," IEEE Transaction on Industry Electronics, vol. 54, no. 5, October 2007.

[11] Dong Hwa Kima, Kaoro Hirota, "Vector control for loss minimization of induction motor using GAPSO," Applied Soft Computing, vol. 8, no. 4, September 2008, Pages 1692-1702.

[12] Chandan Chakraborty, and Yoichi Hori, "Fast Efficiency Optimization Techniques for the Indirect Vector-Controlled Induction Motor Drives," IEEE Transactions on Industry Applications, vol. 39, no. 4 pp. 1070-1076, July/August 2003.

[13] Z. Rouabah, F. Zidani, B. Abdelhadi, "Efficiency optimization of induction motor drive using fuzzy logic and genetic algorithms," ISIE 2008, pp. 737742, June 30-July 22008.

[14] J. Kennedy, R. C. Eberhart, "Particle swarm optimization," Proceedings of IEEE International Conference on Neural Networks," vol. 4, pp. 1942-1948, 1999.

[15] Sakuntala Mahapatra, Raju Daniel, Deep Narayan Dey, Santanu Kumar Nayak, "Induction Motor Control Using PSOANFIS," Elsevier, Procedia Computer Science 48 (2015), pp. 753-768.

[16] V. P. Sakthivel, R. Bhuvaneswari, S. Subramanian, "Multi-objective parameter estimation of induction motor using particle swarm optimization," Engineering Applications of Artificial Intelligence vol. 23, no. 3, April 2010, Pages 302-312.

[17] Radwin H. A. Hamid, Amr M. A. Amin, Refaat S. Ahmed, and Adel A. A. El-Gammal, "New technique for maximum efficiency and minimum operating cost of induction motors based on particle swarm optimization," 32nd Annual Conference on IEEE Industrial Electronics, pp. 1029-1034, 2006.

[18] G. Sousa, "Application of Fuzzy Logic for Performance Enhancement of Drives," Phd Dissertation, Univ. of Tennessee, Knoxvilee, Dec. 1993.

[19] Venkatachalam M, Thangavel s, "Fuzzy Logic Based Performance Improvement of Induction Motor" 2012 IEEE International Conference on Engineering Education: Innovative Practices and Future Trends (AICERA), pp. 1-7, 19-21 July 2012.

[20] Ibrahim M. Alsofyani, , N. R. N. Idris, "A review on sensorless techniques for sustainable reliablity and efficient variable frequency drives of induction motors," Renewable and Sustainable Energy Reviews vol. 24, August 2013, Pages 111-121.

[21] Jung-Sik Choi, Jae-Sub Ko, Ki-Tae Park, "High Performance Control of Induction Motor using GA," International Conference on Control, Automation and Systems 2007 Oct, 17-20, 2007 in COEX, Seoul, Korea.

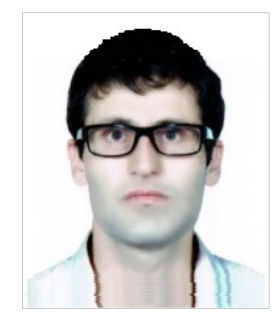

Sadegh Hesari He received his M. Sc. degree in Electrical Engineering from Azad University of Bojnourd and B. S. degree in Electrical Engineering from sadjad University of Mashhad. He is a researcher and an active member of Young Researchers and Elite Club. He is interested in Machine Drive, Power Electronic, Intelligent Controls and Renewable energy.

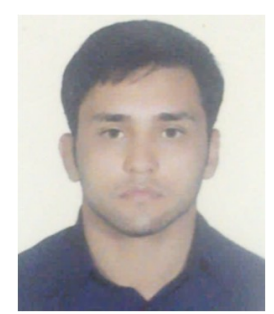

Aghil Hoseini He received his B. Sc and M. Sc degree in Electrical Engineering from Azad University of Bojnourd. His research interests are Machine Drive and Power Electronic. 